\title{
Superconductivity in layered nickel oxides
}

\author{
C N R RAO*, A K GANGULI and R NAGARAJAN \\ Solid State and Structural Chemistry Unit, Indian Institute of Science, Bangalore 560012 , \\ India.
}

MS received 1 February 1989

Abstract. Likely presence of superconductivity in layered nickelates of $\mathrm{K}_{2} \mathrm{NiF}_{4}$ structure is pointed out.

Keywords. Superconductivity; nickel oxides; lanthanum-strontium-nickel oxides.

PACS No. $74 \cdot 70$

Since the discovery of superconductivity in $\mathrm{La}_{2-x} \mathrm{Ba}_{x} \mathrm{CuO}_{4}$ by Bednorz and Müller (1986) just over two years ago, there have been innumerable reports on hightemperature cuprate superconductors (Rao 1988a, b, c, d; Rao and Raveau 1989). The maximum $T_{\mathrm{c}}$ today is close to $130 \mathrm{~K}$. All these cuprates have two-dimensional $\mathrm{CuO}$ sheets just as in $\mathrm{La}_{2-x} \mathrm{Ba}_{x} \mathrm{CuO}_{x} . \mathrm{La}_{2-x} \mathrm{M}_{x} \mathrm{CuO}_{4}(\mathrm{M}=\mathrm{Sr}$ or $\mathrm{Ba})$ is tetragonal at room temperature and becomes orthorhombic at low temperatures, well before the superconducting transition. These oxides are marginally metallic at room temperature and have a nominal mixed valence of $\mathrm{Cu}$. We have been interested in the study of $\mathrm{La}_{2} \mathrm{CuO}_{4}$ and other transition metal oxides of $\mathrm{K}_{2} \mathrm{NiF}_{4}$ structure for some years (Ganguly and Rao 1984; Rao and Ganguly 1987). Thus, we have compared the properties of transition metal oxides of $\mathrm{K}_{2} \mathrm{NiF}_{4}$ structure especially those of the formula $\mathrm{La}_{2-x} \mathrm{Sr}_{x} \mathrm{MO}_{4}(\mathrm{M}=$ transition metal) with the corresponding threedimensional perovskite oxides (Rao et al 1988).

Among these layered oxides, of special interest is $\mathrm{La}_{2} \mathrm{NiO}_{4+\delta}$ which is on the borderline between a metal and an insulator. The oxide shows a metal-insulator transition around $600 \mathrm{~K}$ in the $a b$-plane (Ganguly and Rao 1973; Rao et al 1984). The nickelate generally has an oxygen excess and the magnetic susceptibility is a strong function of $\delta$. For $\delta=+0.001, \chi(T)$ is temperature-independent below $300 \mathrm{~K}$ and for 0.05 there is a small cusp in $\chi(T)$ at $160 \mathrm{~K}$ (Buttrey et al 1986). The presence of long-range quasi two-dimensional antiferromagnetic order below $200 \mathrm{~K}$ was suggested earlier. It is noteworthy that $\mathrm{La}_{2} \mathrm{CuO}_{4}$ has an antiferromagnetic Neél temperature around $290 \mathrm{~K}$ (Mitsuda et al 1987) and shows an orthorhombic-tetragonal transition around $505 \mathrm{~K}$.

$\mathrm{La}_{2} \mathrm{CuO}_{4}$ is suggested to be in a quantum-fluid state wherein the spins are ordered over long distances, but no measurable time-averaged moment is detectable (Shirane et al 1987). Recent neutron scattering studies (Aeppli and Buttrey 1988) show that in

* To whom all correspondence should be addressed. 
$\mathrm{La}_{2} \mathrm{NiO}_{4+\delta}$ also there is a strong influence of the orthorhombic-tetragonal transition $(\sim 240 \mathrm{~K})$ on the magnetic correlations in the paramagnetic state. Furthermore, the in-plane magnetic dynamics as well as the three-dimensional Neél temperature depend strongly on oxygen stoichiometry. It is clear that $\mathrm{La}_{2} \mathrm{NiO}_{4+\delta}$ is very similar to $\mathrm{La}_{2} \mathrm{CuO}_{4+\delta}$ in most respects, the latter also showing a strong dependence of three-dimensional $T_{N}$ on $\delta$. A bove $T_{N}$, there are two-dimensional magnetic correlations in both the oxides. Oxygen-excess $\mathrm{La}_{2} \mathrm{CuO}_{4+\delta}(\delta>0 \cdot 0)$, however, shows superconductivity (Beille et al 1987; Jorgensen et al 1988), but $\mathrm{La}_{2} \mathrm{NiO}_{4+\delta}$ does not.

$\mathrm{La}_{2} \mathrm{NiO}_{4+\delta}$ has two-dimensional $\mathrm{NiO}$ sheets and there is evidence for the presence of oxygen-holes in this oxide just as in the cuprate superconductors (Rao et al 1987, Rao 1988b; Chakraverty et al 1988). Recent studies in this laboratory show that metallic $\mathrm{LaNiO}_{3}$ also has a high proportion of oxygen holes. It seems therefore likely that a two-dimensional nickel oxide consisting of a fair proportion of nominal $\mathrm{Ni}^{3+}$ (or oxygen holes) should show superconductivity at reasonably high temperatures.

Leaving $\mathrm{La}_{2} \mathrm{NiO}_{4+\delta}$, the likely candidate for high $T_{c}$ superconductivity would be oxides of the $\mathrm{Ln}_{2-x} \mathrm{M}_{x} \mathrm{NiO}_{4+\delta}$ where $\mathrm{Ln}=\mathrm{La}, \mathrm{Pr}$ or $\mathrm{Nd}$ and $\mathrm{M}=\mathrm{Ca}, \mathrm{Sr}$ or $\mathrm{Ba}$. Here $\mathrm{Ni}$ is nominally mixed-valent. Unlike $\mathrm{LaNiO}_{3}, \mathrm{LaSrNiO}_{4}$ is an insulator (Mohan Ram et al 1986). Increasing the number of perovskite layers in the $\mathrm{La}_{n+1} \mathrm{Ni}_{n} \mathrm{O}_{3 n+1}$ or $(\mathrm{LaO})\left(\mathrm{LaNiO}_{3}\right)_{n}$ series of which $\mathrm{La}_{2} \mathrm{NiO}_{4}$ is the $n=1$ member, does not help since it only makes the material metallic similar to $\mathrm{LaNiO}_{3}$. A system such as $\mathrm{La}_{2} \mathrm{SrNi}_{2} \mathrm{O}_{7+\delta}$ and $\mathrm{La}_{3} \mathrm{SrNi}_{3} \mathrm{O}_{10+\delta}$ is another possibility. Small amount of $\mathrm{Cu}$ doping $(<10 \%)$ in these layered nickelates would also favour superconductivity.

Preliminary measurements in this laboratory on the layered nickelates have shown indications of superconductivity in the $\mathrm{Ln}-\mathrm{Sr}-\mathrm{Ni}-\mathrm{O}$ system. Although magnetic measurements are dominated by antiferromagnetic interactions due to $\mathrm{Ni}^{2+}$, we see some evidence for the onset of diamagnetism in the $20-80 \mathrm{~K}$ range depending on composition and annealing conditions (figure 1). Details will be published shortly elsewhere.

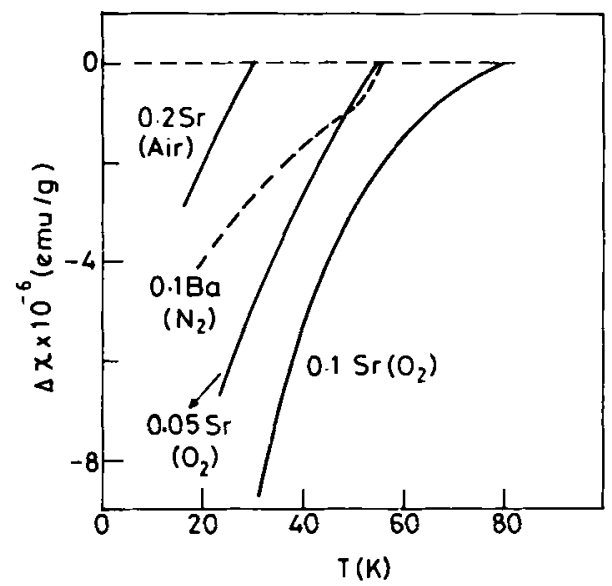

Figure 1. Diamagnetic contribution in $\mathrm{La}_{2-x} \mathrm{M}_{x} \mathrm{CuO}_{4}$ showing onset in the $20-80 \mathrm{~K}$ range.

Thanks are due to the Department of Science \& Technology for support. 


\section{References}

Aeppli G and Buttrey D J 1988 Phy's. Ret. Lett. 61203

Bednorz J G and Müller K A 1986 Z. Phys. B64 187

Beille J et al 1987 C.R. Acad. Sci. Paris 18304

Buttrey D J, Honig J M and Rao C N R 1986 J. Solid State Chem. 64287

Chakraverty B K. Sarma D D and Rao C N R 1988 Physica C156 413

Ganguly P and Rao C N R 1973 Mater. Res. Bull. 8405

Ganguly P and Rao C N R 1984 J. Solid State Chem. 53193

Jorgensen J D. Dabrowski B. Pei S, Hinks D G, Soderholm L, Morosin B, Schiber J E, Venturini E L and Ginley D C 1988 Phys. Ret. to be published

Mohan Ram R A. Ganapathi L, Ganguly P and Rao C N R 1986 J. Solid State Chem. 63139

Mitsuda S, Shirane G, Sinha S K, Johnston D C, Alvarez M S, Vaknin D and Moneton D E 1987 Phys. Ret. B36 822

Rao C N R 1988a J. Solid State Chem. 74147

Rao C N R 1988b Mod. Phys. Lett. B2 1217

Rao C N R (ed.) 1988c Chemistry of oxide superconductors (Oxford: Blackwell)

Rao C N R (ed.) 1988d Proyress in high-temperature superconductivity (Singapore: World Scientific) Vol. 7

Rao C N R and Ganguly P 1987 Curr. Sci. 5647

Rao C N R and Raveau B 1989 Acc. Chem. Res. to be published

Rao C N R, Buttrey D J, Ganguly P, Harrison H R, Sandberg C J and Honig J M 1984 J. Solid State Chem. 52266

Rao C N R, Ganguly P. Hegde M S and Sarma D D 1987 J. Am. Chem. Soc. 1096893

Rao C N R, Ganguly P, Singh K K and Mohan Ram R A 1988 J. Solid State Chem. 7214

Shirane G, Endoh Y, Birgeneau R J, Katsner M A, Hidaka Y, Oda M, Suzuki M and Murakami T 1987 Phys. Rev. Lett. 591613 